\title{
PRODUCT REQUIREMENTS SPECIFICATION PROCESS IN PRODUCT DEVELOPMENT
}

\author{
Göhlich, Dietmar (1); \\ Bender, Beate (2); \\ Fay, Tu-Anh (1); \\ Gericke, Kilian (3) \\ 1: Chair for Methods of Product Development and Mechatronics, Technische Unversität Berlin; \\ 2: Chair of Product Development, Ruhr-University Bochum; \\ 3: Chair of Product Development, University of Rostock
}

\begin{abstract}
Requirements engineering and requirements management are essential sub-processes of product development and are an integrated part of virtually all product development models and industrial process descriptions. Proprietary and context specific processes for working with requirements are used in industrial design practice. However, these are not appropriately reflected in existing process models for product development. Existing standards describe the content and generation of requirements documents but not their integration in the product development process.

The study is based on a retrospective analysis of a set of representative real-world product development projects from automotive industry and rail industry. Comparing the processes downstream the milestone "release of PRD", it was found that subsequent processes to manage requirements and specifications do not differ much with regard to industrial context. Based on this, a model for the product requirements specification (PRS) process is proposed which addresses the gap.
\end{abstract}

Keywords: Requirements, Design process, Product Requirements Specification Process, Case study

\section{Contact:}

Fay, Tu-Anh

Technische Universität Berlin

Product Development Methods and Mechatronics

Germany

tu-anh.fay@tu-berlin.de

Cite this article: Göhlich, D., Bender, B., Fay, T.-A., Gericke, K. (2021) 'Product Requirements Specification Process in Product Development', in Proceedings of the International Conference on Engineering Design (ICED21), Gothenburg, Sweden, 16-20 August 2021. DOI:10.1017/pds.2021.507 


\section{INTRODUCTION}

Requirements engineering and requirements management are essential sub-processes of product development (Loucopoulos, 2005). Accordingly, capturing requirements and working with requirements have been discussed extensively in the literature and both tasks are an integrated part of virtually all product development models and industrial process descriptions (Gericke and Blessing, 2012). While the need to adapt high level procedural process models to the specific design context is widely recognised (Meissner and Blessing, 2006; Gericke et al., 2013a; VDI 2221-2, 2019), its relevance has not yet been addressed with respect to requirements engineering and requirements management processes.

In design practice, proven context specific processes for working with requirements exist, but are mostly focussed on software engineering (e.g. Berkovich et al., 2012 or Katina et al., 2012). However, these concepts are not appropriately reflected in existing process models for product development. The development of modern industrial products usually takes place in distributed and concurrent processes. Thus, the engineering and management of requirements must be handled across different levels, typically between client, manufacturer and suppliers. This paper aims to derive insights from two case studies and proposes a process model for the product requirements specification process which addresses the aforementioned gap.

\section{WORKING WITH REQUIREMENTS IN PRODUCT DEVELOPMENT}

In the following section, we review a variety of process models for product development. We discuss the product requirements specification process (PRS process) as well as relevant standards and guidelines. Based on this in-depth review, we elaborate the research gap we address in this paper.

\subsection{Process models for product development}

A variety of design process models has been created as a means to support designers for planning and documenting their work, as an aid for finding appropriate solutions and decision making, and as a basis for design education (Gericke and Blessing, 2012; Wynn and Clarkson, 2018). In this paper, procedural models with a prescriptive notion are of particular interest, i.e. guidelines such as the VDI 2221 (1993) or design methodologies such as Andreasen and Hein (2000), French (1999), Pugh (1991), or Pahl and Beitz (2007) for mechanical engineering, VDI 2206 (2004) for mechatronics, Tjalve (1979) (industrial design), Phillips et al. (2008) (architecture), Boehm (1988), Gram and Cockton (1996) (software design), to name just a few.

While these models differ with respect to, e.g., the level of detail, their visual appearance (morphology and modelling notation) or coverage of the product lifecycle, they also have some notable similarities. Despite using slightly different terminology, they describe highly similar stages of the process - at least on an abstract level (Gericke and Blessing, 2012). However, the textbook models and guidelines have some shortcomings as design practice evolved through advancements of technology and of working practices in industry (Gericke and Blessing, 2012; Gericke et al. 2013b).

A common aspect of existing process models is the description of a development phase intended to clarify the design task at the beginning of the process (Eisenbart et al., 2011; Gericke and Blessing, 2012). A central result of this stage is a requirements list (sometimes referred to as requirements specification). The requirements list is a "Documentation of required functionality, important influences, constraints and dependencies, as they result from the specific demands, needs and wishes of the stakeholders, the market, etc." (Eisenbart et al., 2011). The requirements list is a generic design state (i.e. the incorporation of all information about a design as it evolves (Dym, 1994)) that exists across all analysed disciplines and is addressed in most process models (Eisenbart et al., 2011). The identification of requirements can be supported by checklists and a range of other methods to cover all stakeholders and lifecycle phases. These methods usually focus on completeness and not necessarily on integrity. Consistency as well as conflicting design goals can be difficult to assess due to missing solution principles or details at this early stage. The V-model emphasises the importance of the continuous system decomposition and the verification and validation of solutions on different levels during system integration (VDI 2206, 2004).

A shortcoming of most design process models is that they often create the impression that once the initial requirements list has been created, this task is completed - even though they usually try to emphasise the need to constantly revise and refine the requirements (either by including arrows 
indicating iterations or within the explaining text). Of course, requirements are not static as the knowledge about requirements co-evolves alongside the knowledge about the design problem (Maher and Poon 1994) resulting in a continuous engagement with the requirements list during the design process (Gericke et al., 2013b).

Some of these shortcomings have been addressed during the revision of the VDI 2221-1 (2019) guideline incorporating much of the research on design processes conducted over the last decades. This model is also used in the revised Pahl/Beitz approach (Bender and Gericke, 2020) see Figure 1.

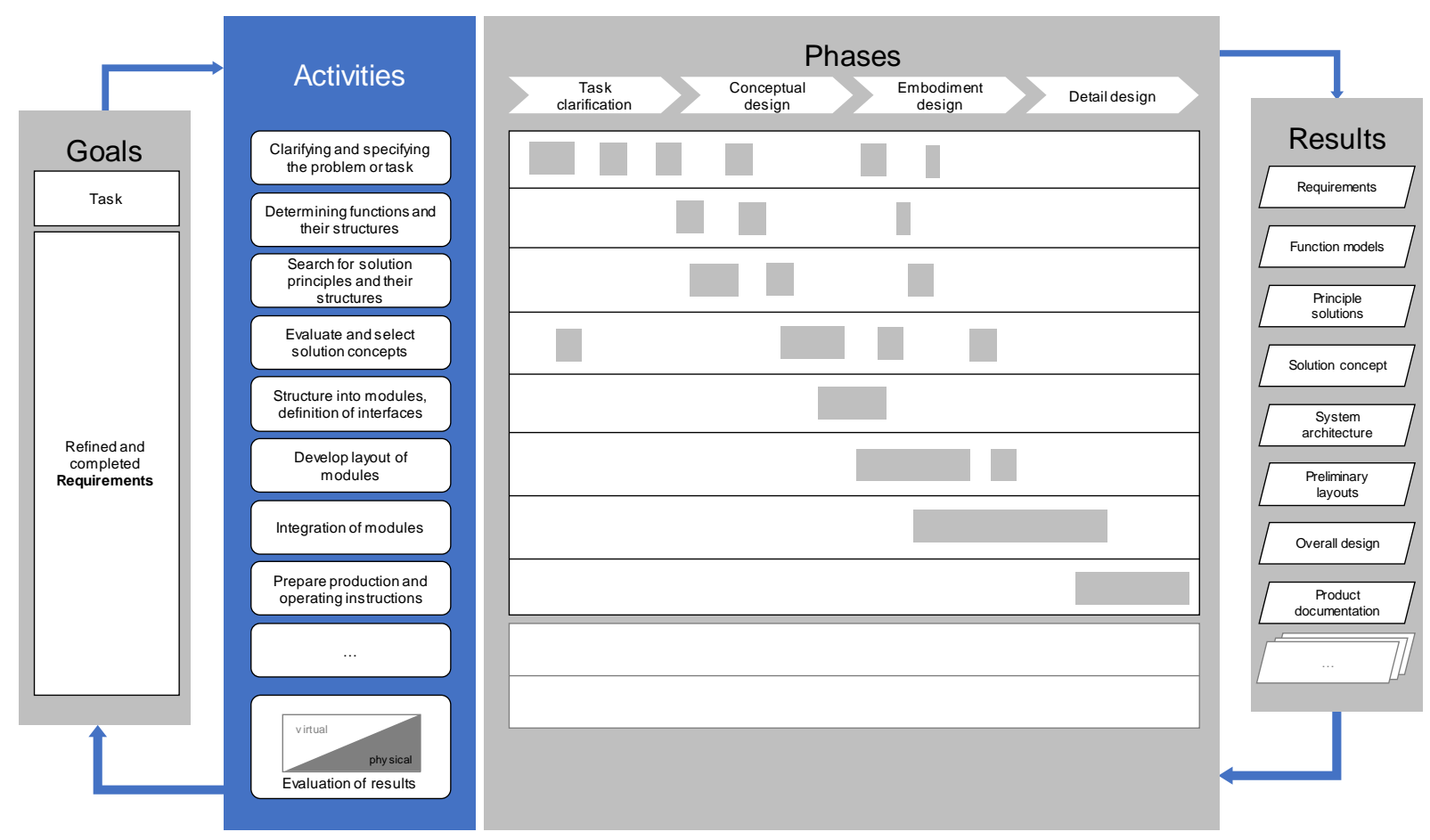

Figure 1. Process model according to VDI 2221 (Bender and Gericke, 2020)

One of the main aspects of this model is its intended flexibility, that addresses the need to adapt high level procedural process models to the specific context of a company/design team. The VDI 2221-2 (2019) provides an overview of important factors (based on Gericke et al., 2013a) that affect the individual adaption, resulting in context specific instances of the generic process model (as shown in Figure 1). Contextual factors can be distinguished into external and internal factors. External factors help to describe influences of, e.g., legislation, market and customer. Internal factors describe influences of, e.g., company, product, team and the individual designer. The guideline also provides some examples of such adaptations for different contexts.

While this process model emphasises that task clarification (i.e. establishing and management of requirements) is a continuous process, no specific guidance for establishing and refining the requirements document is given.

\subsection{Product requirements specification process}

In industry, a process on how to transform customer requirements into technical product specifications has been established with widespread acceptance. The English term product requirements specification process (PRS process) is used to translate the German term "LastenPflichtenheftprozess".

The PRS process (as shown in Figure 2) is based on the idea that the customer for a product development knows what the product should do and why it needs to do it. On the other hand, the contractor developing the respective product has the technical expertise to determine how the product can fulfil its purpose and which technical means are needed to do so. 


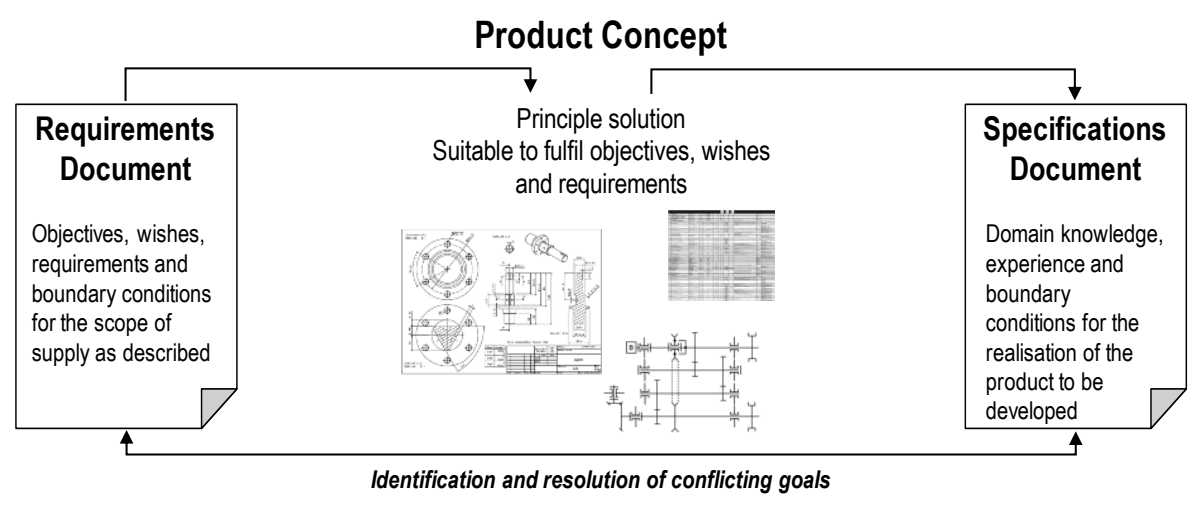

Figure 2. PRS process based on Bender (2020)

The customer (client) for product development can be an external customer as well as an internal customer from within the company. Examples for internal customers are marketing, sales or product management, who define product ideas on the basis of a corporate strategy following market and competition analysis. Using the customers' requirements document, the contractor can then develop a product concept able to satisfy the customers' needs. The suggested product concept obviously reflects the contractors' design context as characterised, e.g., by organisational boundary conditions, specific know-how or production facilities. The specifications document is therefore a contractor specific proposal on how to fulfil the customer requirements and strongly depends on the (assumed, preliminary) problem solution. Customer and contractor can refer to the product concept at hand and agree on how to respond to each and every single customer requirement. The PRS negotiation process is finalised with a revised requirements document (RD) as well as a revised specifications document (SD) which are binding contractual documents for both parties.

The variety of mechatronic products and the complexity of modern systems make distributed and concurrent development at different aggregation levels of the product development process indispensable. Typically, the requirements for each level are managed in different documents, for the overall product in a product requirements document (PRD) and for the subsystems in component requirements documents (CRD).

\subsection{Standards and guidelines for product requirements specifications}

In the guidelines VDI 2519 (2001) and VDI 3694 (2014), procedures for the generation of requirements and specifications documents as well as proposals for structure and criteria for quality assessment are established for automation and material flow systems. Besides general aspects (e.g. description of the initial situation, general key data, data management), the system description, interfaces, system requirements, commissioning, quality and project organisation are dealt with in particular. For medical devices, Shefelbine et al. (2002) proposed a similar procedure.

The German Association of the Automotive Industry (VDA) has proposed an "Automotive Standardised Template for Component Requirements Document" (VDA, 2007), which is based on the compilation of "Best Practices". The VDA approach consists of two parts in which the general requirements (that apply to the overall product and all components) are separated from the specific requirements for the respective component. Furthermore, the document gives a basis for standardised IT support by means of requirements engineering tools. The German Railway Industry Association (VDB) has published a guideline describing the roles and processes of those involved in the generation, commenting and data exchange of requirements documents (VDB, 2020).

For software development, ISO 29148 (2018) provides a standard on systems and software engineering which includes life cycle processes and requirements engineering.

A cross-sector standard or a general guideline for requirements and specifications documents has not yet been established. The above-mentioned guidelines and standards can certainly be transferred to other fields of application, i.e., mechatronics and mechanical engineering. However, the existing standards describe the content and generation of requirements documents but not their integration in the product development process. 


\subsection{Systems engineering and software solutions for requirements management}

Model-based systems engineering (MBSE) is a formalised application of modelling to support system requirements, design, analysis, verification and validation activities beginning in the conceptual design phase and continuing throughout development and later life cycle phases (INCOSE, 2015). In practice, System Modelling Language (SysML) based models have gained the most prevalence in MBSE application. These models are system relationship models and are useful for showing relationships among system functions, requirements, developers, and users (Dick et al., 2017). However, the MBSE approach creates very little insight how to integrate requirements engineering and management in the overall development process.

On the market, a multitude of specific software tools that support requirements management (RM) exist. What they have in common is that individual requirements are stored in a database and documents such as the requirements document for a specific component or system can be generated from this database. Using appropriate interchange formats, the requirements and specifications can be updated and communicated continuously between manufacturer and involved suppliers. However, the RM software tools usually must be adapted to company-specific processes, specific interfaces, business and security requirements.

The multitude of aspects regarding systems engineering and software solutions for requirements management are beyond the scope of this paper, for further details see Göhlich and Fay (2021).

\subsection{Research gap}

Procedural models of the product development process describe the main phases and typical activities on a level of detail that provides guidance while being branch independent at the same time. The tradeoff between context specific tailoring and general applicability leads to simplifications of individual aspects of the development process. Firstly, descriptions of related activities in existing process models for product development usually focus on the collection of requirements rather than their consistency or integrity. Consequently, methodological support when working with requirements emphasises activities to create an initial set of requirements. This neglects (or at least simplifies) the dynamic interrelationship between the understanding of requirements on the one hand and the continuous maturation of the product under development on the other hand. The latter is often referred to as co-evolution of problem and solution. Secondly, since design methodologies obviously focus on supporting the designer, the collection of requirements is described from the developer's point of view.

This does not take into account that product requirements in practice must reflect many different stakeholder's (inconsistent and contradictory) views, which again traditionally gains better attention in the context of software development (e.g. Coughlan and Macredie, 2002). So, the initial set of requirements represents rather a best possible compromise than the ideal requirements to satisfy every single customer need. Thirdly, the shortcomings as discussed in the first and second argument lead to the overemphasis of requirements related activities in early design phases as well as the idea that the collection of requirements must be completed before problem solutions can be developed.

In industrial practice, the PRS process is a collaborative process that needs to consider requirements from internal stakeholders and additional requirements from external engineering partners, first and second tier suppliers of components and sub-systems. The PRS process is embedded in a distributed concurrent development process. This has implications on the handling of information (data storage), consistency, validity, and change management. Moreover, the choice of contracting companies imposes constraints on a development project, which need to be aligned with the requirements base. This might affect the project timeline, budget, fundamental strategic decisions, specific technical expertise, production facilities, as well as human resources or other factors having an influence on the design.

Collaboration between internal and external partners affects the co-evolution and requires the continuous alignment of the requirements base. Depending on the context, these effects require specific PRS processes, addressing individual needs and constraints. While in industrial practice such PRS processes are in place, only few generic descriptions exist so far which could serve as a basis for individual adaptation. In this paper, two context specific PRS processes are described and a proposal of a generalised process is presented. 


\section{STUDY DESIGN AND INDUSTRIAL BACKGROUND}

The study is based on a retrospective analysis of a set of representative real-world product development projects and are summarised in the following two cases. The design context in the first case is from automotive industry and the second case is from rail industry.

First case. Before joining the Technische Universität Berlin, the first author worked in the passenger car development of Mercedes-Benz and Smart vehicles for 21 years. During the development of the first-generation Smart ultra-compact car, the requirements management for the complete noise vibration and harshness (NVH) management which included the acoustic insulation and engine vibration absorbers was evaluated for the study at hand retrospectively (Tomforde and Göhlich, 1995). In this context, both requirements engineering on the product level and requirements management with regard to first tier suppliers were analysed. This comprised the NVH concept in the early design phase including the sign-off process. Furthermore, the complete requirements engineering and management process of a Smart variant with Diesel engine is analysed and covered in this paper. At Mercedes-Benz he led a cross-functional project to conceive and implement a new product change management process including the development and roll-out of a respective workflow software solution for the entire product development division (Göhlich, 2002). In this context the interaction of product change and requirements, including an intercompany integration of first and second tier suppliers was realised. During his last assignment, he was responsible for the concept design and component integration of the Mercedes-Benz S class and CL class vehicles (Knothe et al., 2006; Göhlich, 2007). Aside from project management, he was responsible for the vehicle concept as well as the release and continuous updating of the "Fahrzeug-Lastenheft" (product requirements document).

Second case. Before joining the Ruhr Universität Bochum, the second author worked in the rail industry with Bombardier Transportation for 12 years in an international context. Her function as engineering bid manager for Regional Multiple Units (RMU) involved responsibility for numerous tender and PRS processes in cooperation with suppliers and contractors ranging from small transport operators as well as DB AG, which is reflected in Figure 3. In the project engineer's position, she was responsible for the development of a train concept for a train family (Bender et al., 2007), which specifically involved the early design phases when key requirements needed to be elicited and agreed upon - not only between different engineering domains but also throughout the entire organisation, which broadened her view on the PRS process to new product development. In her following position as product manager RMUs, she was responsible for the development and implementation of the technical and commercial medium and long-term RMU strategy as well as its alignment with actual bid activities. Again, this required the integration of competing requirements from different customers and market segments on the one hand with the company's internal objectives such as standardisation or sourcing strategy with key suppliers on the other hand. Additionally, competitor's products needed to be taken into consideration with regard to price and market position. The perspective on the PRS process now allowed for the integration of competitor analyses. Moving into the engineering line organisation, she was responsible for cross functional integration which involved functions ranging from fire protection via requirements management or industrial design, this required living the PRS process from line function perspective. The last position she held in industry was head of configurations and requirements.

The experiences described for both cases are reflected in the insights on requirements and specification process discussed in the following section.

\section{INSIGHTS FROM INDUSTRY ON REQUIREMENTS AND SPECIFICATION PROCESSES}

When both authors compared their records of the respective PRS processes, it became clear that, despite the contextual differences, a generalised process model may be conceivable. However, a distinction must be made between internal and external design requests. Internal design requests are internally defined by the manufacturer, as is common in the automotive industry, for example, when new vehicles are developed. It is also common in many other industries. An external design request occurs when a client releases a tender for the development and supply of a product to potential contractors (bidders). This is common in plant construction or in the development of rail vehicles, where a transport operator, such as Deutsche Bahn, prepares tenders and the rail vehicle manufacturers then submit corresponding offers. These two cases are described in the following sections and are 
illustrated in Figure 3. Both are based on concrete industrial product development projects. However, a generalised nomenclature has been introduced, to make both cases comparable and to protect the intellectual property of the respective companies.

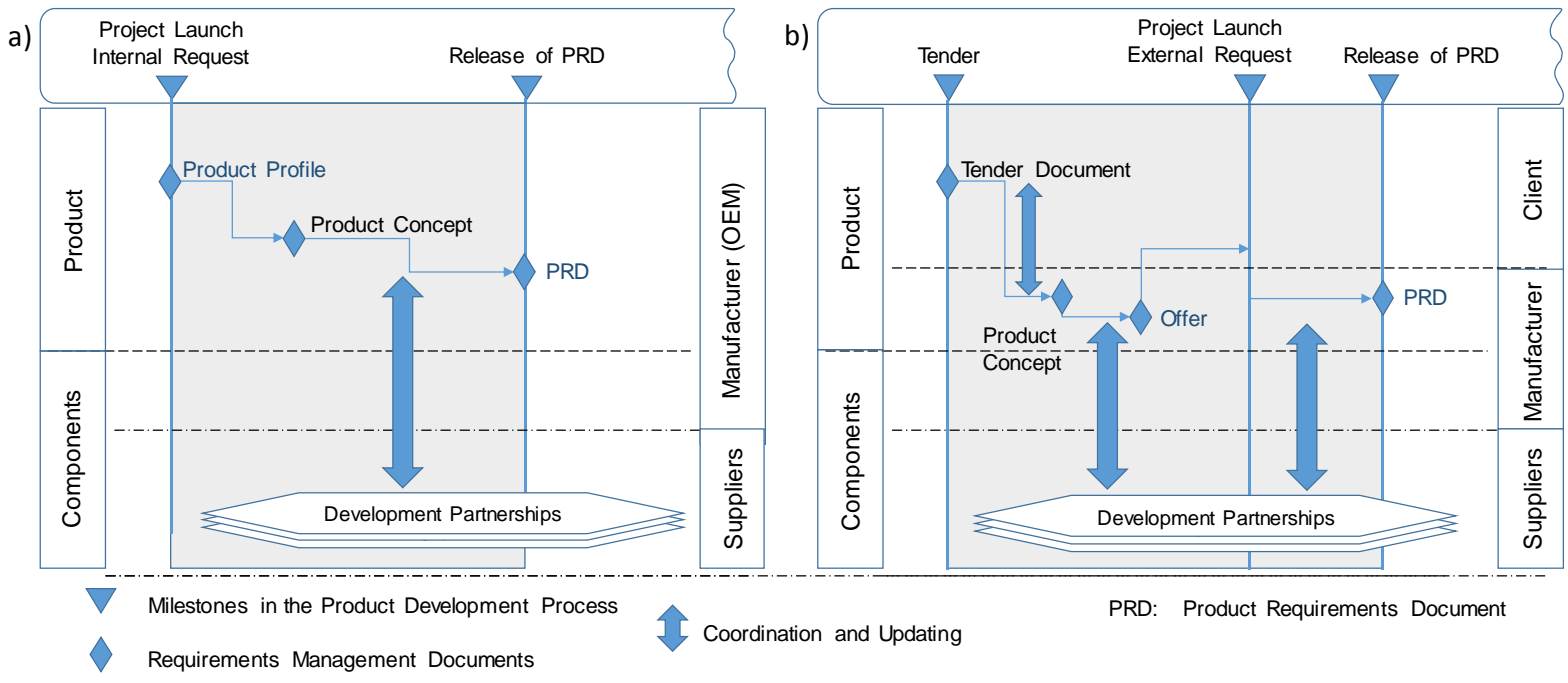

Figure 3. Development process of product requirement document for (a) internal design
request and (b) for external design request

Figure 3a shows the generation of the product requirements document (PRD) for an internal design request. Here, only two levels (product and components) and the cooperation between the manufacturer (often also referred to as original equipment manufacturer, or OEM) and its direct suppliers (often referred to as Tier 1) are considered as examples. In real development processes, direct suppliers often work together with additional sub-suppliers (Tier 2, 3...N). In the planning phase, fundamental strategic decisions are made, overall targets and the framework for the development of a product or even for an entire product family are determined by the OEM. At project launch, the basic requirements and boundary conditions are defined in a product profile. However, at this rough level, it is often not yet possible to fully identify the conflicting targets. In the product conception phase, the targets are worked out in more detail and contradictions typically become transparent. To resolve these contradictions, further adjustments of the targets are often unavoidable. On this basis, a product concept is created, higher-level targets are translated into specific requirements. The product concept describes both the overall product - in the case of a vehicle, e.g., overall dimensions and driving performance - and the essential components such as the drive system or chassis. The product concept is further detailed in a product requirements document. In this process, conflicts of targets again arise which must be identified and resolved. For this purpose, it is often useful to form development partnerships in the early stages and to involve potential suppliers in the coordination process even without a formal agreement, as shown in Figure 3a.

In the case of an external design request, in addition to the manufacturers and the suppliers, a third stakeholder comes into play, the client. The client is an external customer asking for a specific product to be developed by the manufacturer. In the public sector, this procurement activity is connected to an official tender process. Figure $3 \mathrm{~b}$ shows the process. The client provides a tender document. On this basis, the manufacturer, in accordance with the client, develops a product concept, which is not necessarily free of conflicts. In the next step, these conflicts are resolved, usually in cooperation with suppliers, and the manufacturer prepares an offer (VDB, 2020). If a contract is awarded to the manufacturer, the actual project launch takes place and offer and tender document are subsequently further developed into a product requirements document (PRD) to be released.

\section{MODEL FOR PRODUCT REQUIREMENTS SPECIFICATION PROCESS}

The generation, release and update of requirements documents are essential parts of product development and these "deliverables" are important milestones in a general frame plan, which is a fundamental management tool in virtually all product development projects. The process to generate the PRD is, according to the authors' experience, context specific. This is evident for the macroscopic 
processes, as shown above, but also for the specific requirements engineering which includes identification, analysis, prioritising, specification and structuring of requirements. However, comparing the processes downstream the milestone "release of PRD", it was found that subsequent processes to manage requirements and specifications do not differ significantly with regard to industrial context. Based on this comparison, a generalised model for the product requirements specification process (PRS process) is proposed in Figure 4.

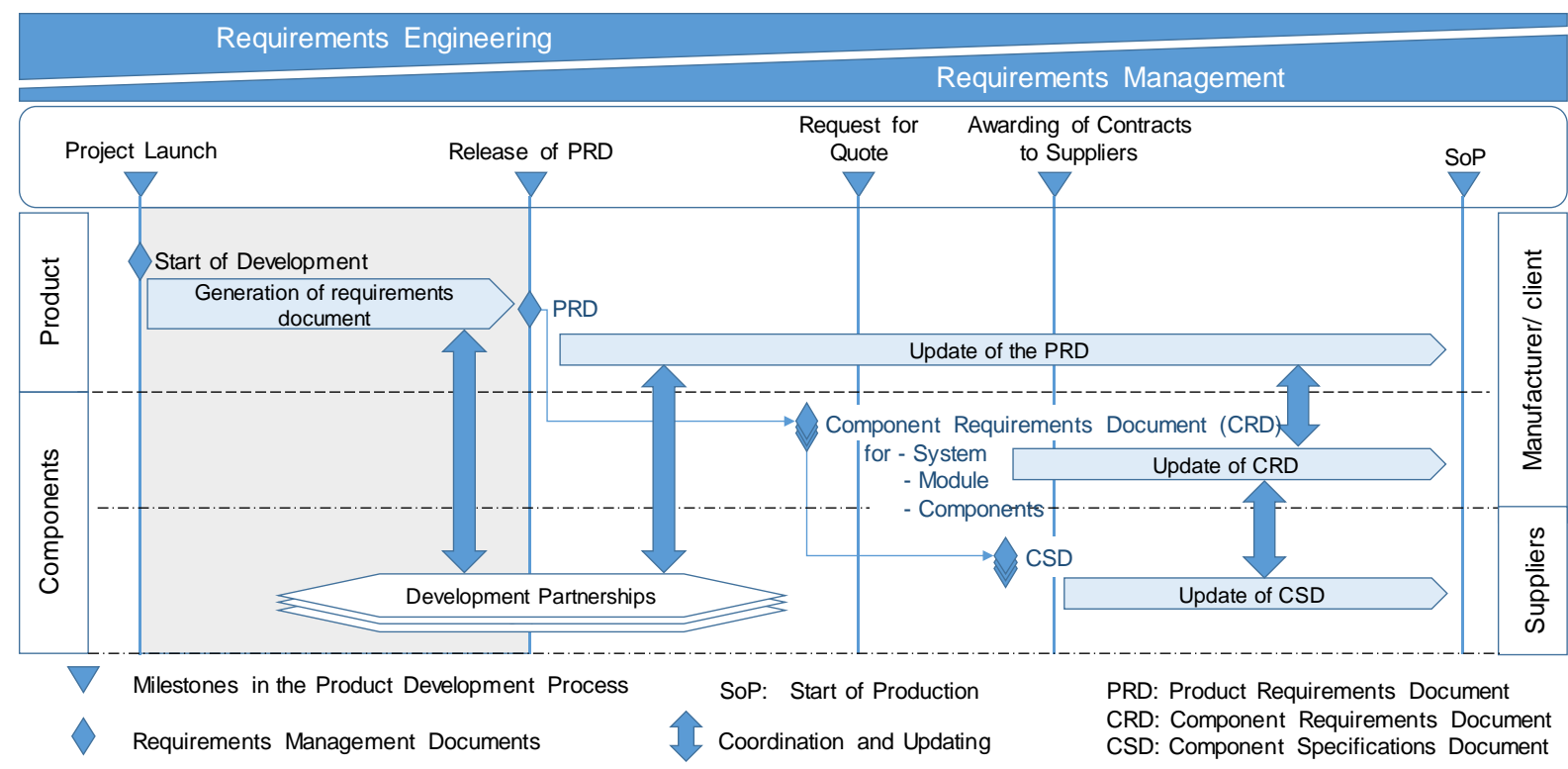

Figure 4. Generic model for PRS process based on Göhlich and Fay (2021)

At project launch, the first revision of a requirements document is generated, usually in cooperation between client, manufacturer and supplier. The differences in the generation of the product requirements document (PRD) for internal versus external design request may be taken into account by substituting the phase from project launch to release of PRD (grey area in Figure 4) by the processes depicted in Figure 3a and $3 \mathrm{~b}$.

From release of PRD, both cases can be described appropriately with a unified model. An agreed PRD is the compulsory basis for further product development both at the manufacturer internally and for the cooperation of the manufacturer with the suppliers. Figure 4 shows how component requirements documents (CRD) for systems, modules and components are developed based on the PRD. These CRDs summarise all requirements of the manufacturer (or client) regarding the performance and scope of supply of the components and are an essential part of the requested documents. On this basis, the suppliers prepare offers and component specifications documents (CSD), which describe the realisation of the requirements. If necessary, the supplier also points out the requirements that are neglected or fulfilled in a modified form using so-called clause-by-clause comments (VDB, 2020). Here, every single requirement is commented by the contractor with regard to its validation and verification.

During the product development process, requirements are refined, revised or changed. When released initially, there might be a considerable gap between requirements and specifications. Typically, this gap is closed in a co-evolution process between problem and solution as shown in Figure 5.

This convergence between a specific requirement and its corresponding specification leads to an ongoing update of the relevant documents which is documented in discrete revisions. In our process model, this co-evolution process is accounted for by the continuous update of requirements and specifications documents and the interaction between client, manufacturer and supplier. In industrial practice RM software tools provide "history" and "traceability" information (Dick et al., 2017) which enable an agile and transparent cooperation between manufacturer and supplier. 


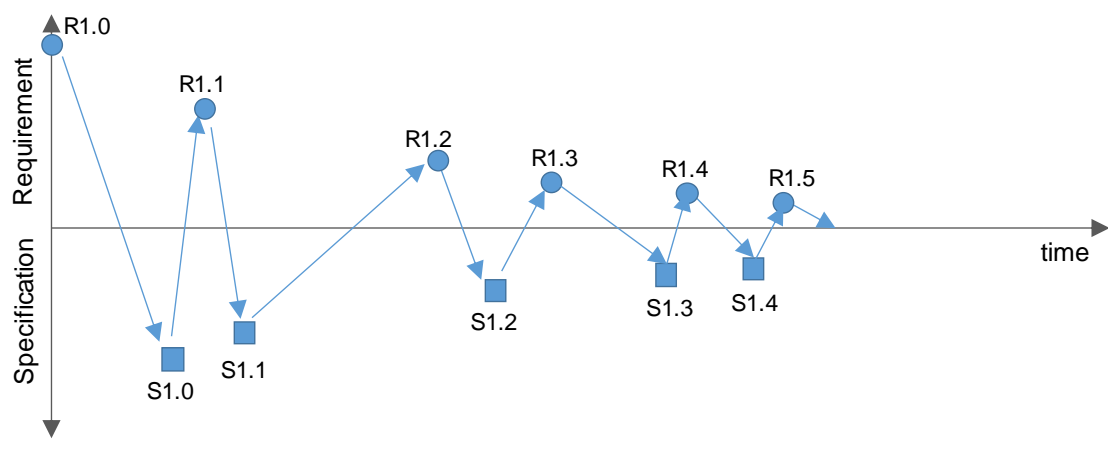

Figure 5. Co-evolution process of requirement and specification

Typically, the update of requirements and specifications is accompanied by engineering design changes. Changing one particular function or component may affect other components, which in turn may have severe consequences for the realisation of related functions, manufacturing process, product cost etc. These conflicts have to be recognised and solved with a transparent and effective decisionmaking process. A rigorous change management (including detailed functional and cost analysis) must be based on clear targets and requires coordination between all stakeholders. Based on the industrial case studies, the release of PRD was identified as a suitable milestone from which engineering changes should be supported by a software-based change management workflow. The complex interaction of requirements and engineering change cannot be discussed here in more detail; a good overview on this topic is given in Jarratt et al. (2011).

As the authors strongly recommend the approach given in VDI 2221-1 (2019), the compatibility of the proposed PRS process model was investigated. When planning a product development process, specific contextual factors must be taken into account. VDI 2221-2 (2019) identifies a total of ten groups of contextual factors which are of particular importance for process design. Five of these ten factors are addressed in the proposed PRS model. These are in detail: Customer, supplier, project management, expectations of development results, development order.

According to VDI 2221-2 (2019), the design of the specific product development process requires a context-sensitive synthesis of the activities of the general model of product development with experiences that are already available to the company. Alternatively, the use of reference processes is suggested. The presented generic process model provides exactly such a reference process for the subprocess product requirements specification. For a specific project or for a specific design request, the procedures and milestones from the PRS process can easily be transferred into a company-specific project plan.

\section{DISCUSSION AND CONCLUSION}

Working with requirements is a crucial task in any product development project, the thorough implementation and the effective execution of a requirements specification process (PRS process) is a key success factor. In this regard, generation, release and update of product requirements documents (PRD) play an important role. Several high-level procedural process models can be found in the literature and the need to adapt such models to the specific design context is widely recognised. The adaptation of requirements engineering and requirements management from high level models to "real world" process descriptions, so far, had to be performed based on proprietary experiences of individual companies and their project management teams. When analysing existing standards, it was found that content and generation of requirements documents are described, but not their integration in the product development process.

The presented generic PRS process is derived from industrial expertise, it reflects the insights gained by the authors over several years in the rail and automotive industry. Based on the comparison of both cases, the authors found relevant differentiating factors in the (upfront) process to generate the PRD. This part of the PRS process is highly context specific, it depends on the initiation of a development project (internal vs. external) and the type of client-customer relationship (direct integration vs. market perspective). Additionally, the degree of formalisation of PRS process is high in case of official tender and external project launch compared to an internal project launch. However, for both cases, generalised models could be derived in form of waterfall process charts. 
The release of a PRD is an important milestone which triggers subsequent development activities. When comparing the processes downstream the milestone "release of PRD", it was found that, for both cases, subsequent processes to manage requirements and specifications do not differ much with regard to industrial context. A generalised and unified model for the PRS process could be derived, again in form of a waterfall chart.

Complex products are typically developed in a close collaboration between manufacturer and suppliers. This interaction is reflected in the PRS process model. The high-level PRD serves as the obligatory requirements base for the interaction between manufacturer and suppliers. Depending on the scope of supply, component requirements documents (CRD) are developed which serve as a basis for specifications documents (SD).

Typically, a strong engineering background is necessary for the generation of requirements documents (PRD and CRD). Hence, in both industrial cases it was found that the overall responsibility for these documents is assigned to functions related to product development. Still, requirements must be agreed with all relevant stakeholders and checked for consistency. The binding definition and coordination with all stakeholders is carried out by cross-functional and cross-divisional decision-making bodies at the points in time defined by the corresponding milestones.

The co-evolution of problem and solution make a continuous alignment of the PRD and CRD necessary thus the proposed PRS process must be accompanied by a rigorous engineering change management which includes relevant stakeholders from the manufacturer and supplier. However, this aspect could not be discussed in detail within the scope of this paper.

The generalised model for the product requirements specification process (PRS process) can help to close the gap between high-level product development process models and the in-depth but proprietary industrial process descriptions. Additionally, the model deepens the understanding for the activities related to requirements engineering and management between client, manufacturer and suppliers at different levels. A common understanding of the joint process allows for better communication and cooperation between all stakeholders involved in the PRS process.

In general, the presented PRS process model provides a considerable advancement to the product development process models described in guidelines and textbooks. In particular, the model provides a reference process which augments the new version of VDI 2221. The PRS process in its current form reflects the design context of automotive and rail industry. However, the authors expect that the presented PRS model can be easily adapted to suit other contexts. It should be possible to generalise the case specific PRD generation within a similar development context. It seems very likely that the findings from the automotive industry can be generalised to other mass-produced products (e.g. household appliances), respectively the rail industry case should be representative for low volume production and plant engineering.

The generalisation, beyond the industrial cases analysed here, needs to be verified, which will be subject to future studies. The authors hope that this work supports the exchange among practitioners and researchers concerning the product requirements specification process. This paper may as well serve as a basis to introduce engineering students into this topic which is of outmost importance for successful product development.

\section{REFERENCES}

Andreasen, M. M. and Hein, L. (2000), Integrated Product Development. Lyngby: Institute for Product Development, Technical University of Denmark

Bender, B. (2020), "Requirements Engineering in the Context of IDE", Integrated Design Engineering, Vajna S. (eds), Springer, Cham. https://doi.org/10.1007/978-3-030-19357-7_19

Bender, B., Derdulla, T., Genersch, J. (2007), "Talent 2 - Fit für die Zukunft", ZEVrail Glasers Annalen 131, Vol. 9, pp. 340-351

Bender, B., Gericke, K. (Eds.). (2020), Pahl/Beitz Konstruktionslehre (9th ed.), Springer, Berlin. https://doi.org/10.1007/978-3-662-57303-7

Berkovich, M., Leimeister, J. M. et al. (2012), "A requirements data model for product service systems", Requirements Engineering, 19 (2), pp. 161-186. https://doi.org/10.1007/s00766-012-0164-1

Boehm, B. W. (1988), “A spiral model of software development and enhancement”, Computer, 21(5), pp. 61-72. https://doi.org/10.1109/2.59

Coughlan, J.; Macredie, R. D. (2002), "Effective communication in requirements elicitation: a comparison of methodologies" Requirements Engineering, 7(2), pp. 47-60. https://doi.org/10.1007/2fs007660200004 
Dick, J., Hull, E., Jackson, K. (2017), Requirements Engineering (4th ed.), Springer, Berlin, Heidelberg. https://doi.org/10.1007/978-3-319-61073-3

Dym, C. L. (1994), Engineering Design - A Synthesis of Views, 1994, Cambridge University Press

French, M. J. (1999), Conceptual design for engineers (3rd ed.), Springer, London

Eisenbart, B., Gericke, K., Blessing, L. (2011), “A framework for comparing design modelling approaches across disciplines”, in Culley, S. J., Hicks, B. J., et al. (Eds.), Proceedings of the 18th International Conference on Engineering Design (ICED11), Copenhagen, Norway, August 15-18, The Design Society, Glasgow, pp. 344-355.

Gericke, K. and Blessing, L. (2012), “An analysis of design process models across disciplines”, in Marjanovic, D., Storga, M., et al. (Eds.), Proceedings of the 12th International Design Conference DESIGN 2012, Dubrovnik, Croatia, May 21-24, Cavtat: Faculty of Mechanical Engineering and Naval Architecture, University of Zagreb; The Design Society, Glasgow, pp. 171-180.

Gericke, K., Meißner, M., Paetzold, K. (2013a), "Understanding the context of product development", in Lindemann, U., Venkataramen, S., et al. (Eds.), Proceedings of the International Conference on Engineering Design, Seoul, Korea, August 19-22, Vol. 3 DS75-03. The Design Society, Glasgow

Gericke, K., Qureshi, A. J., Blessing, L. (2013b), “Analyzing transdisciplinary design processes in industry - An overview” Proceedings of the ASME Design Engineering Technical Conference, Portland, Oregon, USA. August 4-7. https://doi.org/10.1115/DETC2013-12154

Göhlich, D. (2002), "Produkt-Datenmanagement in der Mercedes-Benz Pkw-Entwicklung“, invited key note at ETH Zürich, 31 October 2002, http://webarchiv.ethz.ch/sim/htm/_Lehre_/ewf_pdf/EWF_02_03/Vor102_Göhlich_Teil_1..pdf

Göhlich, D. (2007), "Innovationen der Fahrzeugtechnik am Beispiel der Mercedes-Benz S-Klasse", in Schindler, V. (Eds.), Forschung für das Auto von Morgen, Springer, Berlin, Heidelberg. https://doi.org/10.1007/978-3-540-74151-0_2

Göhlich, D. and Fay, T.-A. (2021), “Arbeiten mit Anforderungen: Requirements Management”, Pahl/Beitz Konstruktionslehre (9th ed.), Bender, B., Gericke, K. (Eds.), Springer, Berlin, Heidelberg

Gram, C. and Cockton, G. (Eds.) (1996), Design Principles for Interactive Software, Springer, Boston. https://doi.org/10.1007/978-0-387-34912-1

INCOSE (2015), “Managing Requirements for Design”, Infrastructure Working Group, International Council On Systems Engineering, INCOSE-PI-2015-003-1.0, Version 1.0.

ISO 29148 (2018), ISO/IEC/IEEE 29148 Systems and software engineering - Life cycle processes Requirements engineering

Jarratt, T.A.W., Eckert, C.M., et al. (2011), "Engineering change: an overview and perspective on the literature", Research in Engineering Design, 22, pp. 103-124. https://doi.org/10.1007/s00163-010-0097-y

Katina, P. F.; Keating, C. B. et al. (2012),’System requirements engineering in complex situations" Requirements Engineering, 19(1), pp. 45-62. https://doi.org/10.1007/s00766-012-0157-0

Knothe, F., Göhlich, D. et al. (2006), "Die neue CL-Klasse von Mercedes-Benz”, ATZ - Automobiltechnische Zeitschrift, 108, pp. 800-813. https://doi.org/10.1007/BF03221821

Loucopoulos, P. (2005), "Requirements engineering”, in Design Process Improvement, Clarkson P.J., Eckert C. (Eds.), Springer, London

Maher, M. L., Poon, J. (1994), “Modeling Design Exploration as Co-Evolution”, Computer-Aided Civil and Infrastructure Engineering, 11(3), 195-209. https://doi.org/10.1111/j.1467-8667.1996.tb00323.x

Meißner, M. and Blessing, L. (2006), "Defining an adaptive product development methodology", Proceedings of the 9th International Design Conference (Design 2006), Dubrovnik, Croatia, pp. 69-78.

Pahl, G., Beitz, W., et al. (2007), Engineering Design - A Systematic Approach (3rd ed.), Springer, Berlin

Phillips, R., Toole, W., Royal Institute of British Architects (2008). Plan of work: Multi-disciplinary services. London: RIBA publ.

Pugh, S. (1991), Total design: Integrated methods for successful product engineering, Prentice Hall

Shefelbine, S., Clarkson, J., et al. (2002), "Good Design Practice for Medical Devices and Equipment Requirements Capture", University of Cambridge Engineering Design Centre, Cambridge, ISBN 1-902546$10-5$

Tjalve, E. (1979), A Short Course in industrial design, Newnes-Butterworth, London

Tomforde, J., Göhlich, D. (1995), "Konzeptwettbewerb und Entwicklungspartnerschaft am Beispiel Motorlagerung eines Kleinfahrzeuges“, Tagung im Haus der Technik: Elastische Lagerungen im Automobilbau, Essen 1995

VDA (2007), Automotive VDA-Standardvorlage Komponentenlastenheft (1st ed.), Henrich Druck + Medien GmbH \& Co. KG, Frankfurt am Main

VDB (2020),"VDB-LEITFADEN Datenaustausch beim Anforderungsmanagement in der bahntechnischen Wertschöpfung“, Verband der Bahnindustrie in Deutschland, Berlin, https://bahnindustrie.info/fileadmin/Leitfaeden_DE/200108_VDBLeitfaden_Anforderungsmanagement.pdf

VDI 2206 (2004), VDI 2206 - Design methodology for mechatronic systems. Beuth, Berlin 
VDI 2221 (1993), Methodik zum Entwickeln und Konstruieren technischer Systeme und Produkte, Beuth, Berlin

VDI 2221-1 (2019), VDI 2221 Blatt 1: 2019-11 Entwicklung technischer Produkte - Modell der

Produktentwicklung, Beuth, Berlin

VDI 2221-2 (2019), VDI 2221 Blatt 2: 2019-11 Entwicklung technischer Produkte und Systeme - Gestaltung individueller Produktentwicklungsprozesse, Beuth, Berlin

VDI 2519-1 (2001), VDI 2519 Blatt 1 Vorgehensweise bei der Erstellung von Lasten-/Pflichtenheften, Beuth, Berlin

VDI 3694 (2014), VDI 3694 Lastenheft/Pflichtenheft für den Einsatz von Automatisierungssystemen, Beuth, Berlin

Wynn, D. C. and Clarkson, P. J. (2018), "Process models in design and development", Research in Engineering Design, Springer, London, 29(2), pp. 161-202. https://doi.org/10.1007/s00163-017-0262-7 